\title{
Patrimonio e identidad de Santo Domingo y la gestión del producto turístico cultural de Lima
}

\section{Heritage and identity of Santo Domingo and management of the cultural tourism product of Lima}

\author{
Nieves Cecilia Castillo Yui* \\ Escuela Profesional de Turismo y Hotelería, \\ Universidad de San Martín de Porres, Perú
}

\section{Resumen}

La iglesia y convento de Santo Domingo integran uno de los más importantes y reconocidos conjuntos monumentales de la ciudad de Lima debido a su valor histórico, religioso, arquitectónico y artístico. Se plantea por ello, como objetivo de esta investigación, determinar si el patrimonio e identidad de Santo Domingo influyen en la gestión del producto turístico cultural de Lima. Además, se desarrollan los conceptos de patrimonio e identidad, considerando que ambos actúan para consolidar y sustentar las bases de la nacionalidad peruana sobre un territorio de pertenencia con historia, pasado, presente y futuro; reconociendo la formación de la identidad como punto de partida para la valoración, cuidado y promoción. También, se mencionan instituciones que desarrollan programas turísticos con éxito, gracias a la gestión del producto. Se destaca, asimismo, la importancia y trascendencia de la obra evangelizadora de los dominicos en el Perú.

Palabras clave: patrimonio cultural, identidad, evangelización, gestión, turismo.

Este es un artículo Open Access bajo la licencia Creative Commons Atribución-NoComercial-Compartirlgual 4.0

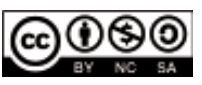




\begin{abstract}
The church and convent of Santo Domingo make up one of the most important and recognized monuments of the city of Lima due to their historical, religious, architectural and artistic value. The objective of this research is to determine if the heritage and identity of Santo Domingo influence the management of the cultural tourism product of Lima. In addition, concepts of heritage and identity are developed, considering that both act to consolidate and support the bases of Peruvian nationality over a territory of belonging with history, past, present and future, and recognizing the formation of identity as a starting point for valuation, care and promotion. This paper also mentions the institutions that successfully develop tourism programs thanks to the management of the product, and highlights the importance and significance of the evangelizing work of the Dominicans in Peru.
\end{abstract}

Keywords: cultural heritage, identity, evangelization, management, tourism.

\title{
Introducción
}

La iglesia y convento de Santo Domingo constituyen uno de los más importantes y reconocidos conjuntos monumentales religiosos de la ciudad de Lima. Alberga en sus antiguos muros el testimonio de vida de nuestros santos peruanos, venerados por nacionales y extranjeros, como son Santa Rosa de Lima, San Martín de Porres y también San Juan Macías, quién no nació en el Perú, pero vivió en el país muchos años comprometido con los más necesitados. Además, la Orden fue cuna de dos grandes universidades, la Universidad Nacional Mayor de San Marcos, decana de América, creada en el siglo XVI; y la Universidad de San Martín de Porres, fundada a mediados del siglo $\mathrm{XX}$.

Considerando, a la Orden dominica poseedora de un valor histórico, religioso, arquitectónico, artístico y evangelizador en el Perú, se plantea la necesidad de realizar la presente investigación, teniendo como objetivo determinar en qué medida el patrimonio e identidad de Santo Domingo influye en la gestión del producto turístico cultural de la ciudad de Lima. 
El patrimonio cultural es lo que fortalece la integridad de sus habitantes, estableciendo una relación estrecha entre lo social y territorial, precisamente, es así que la cultura peruana ha formado y viene formando su identidad. Las manifestaciones de patrimonio cultural material son recursos para el turismo, que se convierten en atractivos después de acondicionarlos con los servicios que corresponden. Sin embargo, una ciudad histórica monumental no necesariamente es turística, porque entendemos que no es fácil gestionar el turismo e integrarlo a una estructura urbana que no ha sido preparada para ello.

Cabe mencionar a Pérez de Cuéllar (como se citó en United Nations Educational Scientific and Cultural Organization - UNESCO, 1997) quien al referirse a la cultura manifiesta:

Cultura significa un cambio en nuestros modos de pensar, actuar, en cómo nos percibimos; cambio en nuestra interacción con los demás, y cambio en cómo creamos y sostenemos el medio ambient y las comunidades en que vivimos (...) la cultura es la transmisión de comportamiento pero también una fuente dinámica para el cambio, la creatividad, la libertad y para el despertar de nuevas oportunidades. (pp. 6-10)

En este contexto, surgen interrogantes sobre qué características tienen quienes comparten territorio, historia, patrimonio y cultura, y qué los hace sentirse peruanos, cuando la característica principal es la diversidad, el mestizaje. Delimitarlo, se convierte en una ardua tarea, más aún si en la actualidad existe una crisis de valores que afecta al país; donde no parece importarnos las consecuencias de nuestros actos y se perdió el respeto por sí mismo y por los demás, así como la voluntad de luchar por un bien común.

Frente a la crisis de valores existente, Leuridan (2014) plantea:

La pérdida de valores en el mundo construido por los adultos incluye muchos aspectos característicos de la postmodernidad: mundo tecnocientífico con un pensamiento positivista que excluye los valores (...) la persona se vuelve indiferente hacia sí misma y deja de actuar 
porque nada le interesa, ni le parece que vale la pena el esfuerzo, sobre todo en el sector estatal. La imagen del hombre que se impone es la del que produce y consume. (pp. 16-17)

Los ciudadanos que no respetan su patrimonio porque no saben apreciar, cuidar y conservar «lo suyo», no tienen identidad; es decir, pierden ese sentimiento de apego o pertenencia que los hace sentirse orgullosos de lo que tienen y de dónde vienen.

El Perú actual aún se debate entre dos tendencias marcadas en busca de la identidad. Por un lado, tenemos la que pertenece a la cultura Inca, considerada como una de las grandes civilizaciones madres del mundo antiguo, autóctona y original; y por otro lado, la que pertenece a la cultura occidental traída por los españoles. Al producirse la conquista y dominación se da lugar a la transculturización y se pierden muchas características y costumbres del Imperio incaico, pero también la fuerza de la costumbre y lo arraigado de lo autóctono, permite mantener creencias que se fusionan con las nuevas formas de vida y costumbres, lo que da como resultado una nueva cultura mestiza. Se genera un sincretismo.

Es preciso mencionar que la orden dominica tuvo marcada influencia y orientación en la formación de una nueva cultura en la población de entonces, debido a su labor evangelizadora, lo cual desarrollaremos más adelante.

Ahora bien, la globalización en la actualidad marca una tendencia a generalizar con una misma simbología e idioma, estándares, características, normas y procesos, lo que ejerce un cambio significativo en la cultura, pero no en la esencia misma. Por ello, lo importante en la gestión del producto turístico es el respeto por el patrimonio y la identidad, porque al elaborar el producto y mostrarlo se evidencia esa sensibilidad de valorar lo propio, sentir orgullo de lo nuestro y no ir por lo más fácil que es copiar formas y costumbres.

A propósito de lo expuesto, la actividad turística, desde el enfoque de la gestión del patrimonio es abordada en este trabajo ya que la gestión del producto turístico cultural en la ciudad de Lima debe optimizarse con el 
objetivo de contar con un producto turístico sostenible y consolidado. Debemos tener en cuenta que no basta con la descripción de los numerosos elementos patrimoniales, dado que turismo es una actividad multisectorial con compromiso y también una herramienta de desarrollo para valorar el patrimonio.

Se hace necesario, por lo tanto, un cambio de actitud, tomar conciencia de lo que Lima representa para el turismo, sobre todo en la comunidad y sector empresarial. Los valores arquitectónicos son obras de arte que evidencian la importancia de otros tiempos y que se tornan frágiles al estar expuestos a la contaminación y descuido de sus infraestructuras. Se hace imprescindible aplicar políticas culturales cumpliendo el rol de salvaguarda de estos patrimonios.

El Conjunto Monumental de Santo Domingo es, efectivamente, testimonio de valores tangibles e intangibles, que se ve amenazado por el paso inevitable del tiempo y la falta de atención de las autoridades e instituciones de la localidad. Es importante atender este patrimonio para que no pierda su integridad como atractivo cultural y acondicionarlo como atractivo turístico, implementándolo con servicios que permitan su visita, logrando consolidar una imagen que sea producto de una buena gestión. Hace falta tener real conocimiento cualitativo y cuantitativo del patrimonio y toma de conciencia de la población, en el ámbito empresarial y gubernamental. Por su parte, los programas de recuperación de Lima cuadrada de la Municipalidad Metropolitana de Lima y la Empresa Municipal Inmobiliaria de Lima (EMILIMA) son entidades que sustentan y apoyan la recuperación del centro histórico de Lima por estar inscrito y ser parte de la lista del Patrimonio Mundial de UNESCO.

\section{Entidades religiosas que han gestionado trabajos en el plano turístico}

En el ámbito nacional e internacional existen ejemplos que pueden ilustrar las acciones de entidades religiosas que gestionan trabajos en el plano turístico, es decir, que proponen buenas prácticas que se constituyen como normas. Estos lugares turísticos son implementados con fines sociales para beneficio de la comunidad. Mencionaremos algunos casos que se encomiendan al turismo para salvar el patrimonio: 
En Burgos, España, donde Santo Domingo de Guzmán fundó la Orden de los Dominicos, su Casa Madre, es centro de congresos. Y en Caleruega, el monasterio de Santo Domingo es una sala de conservación y exhibición de esculturas y pinturas, así como el conjunto arquitectónico de Torreón de los Guzmanes es acondicionado para actos culturales. Asimismo, se ha restaurado la Bodega de Juana de Aza, madre del fundador dominico. Son gestionados por los propios frailes dominicos.

En la ciudad ecuatoriana de Quito se han intervenido espacios urbanos e iglesias que tuvieron un proceso de restauración y posterior gestión cultural en favor de su conservación. Salgado-Gómez (2008) señala:

Las nociones de Patrimonio Cultural, como parte de la gubernamentalidad, apuntan a salvaguardar lo material, mostrando una homogeneidad, un orden, ajenos a los procesos, las luchas y conflictos que poblaron las calles, plazas y casas de la vieja ciudad, y que hoy han sido desplazados por no entrar en la categoría de lo «memorable», de lo blanco-mestizo, lo ordenado, y lo limpio. (p. 23)

Es decir, se analiza la importancia de la conservación y restauración patrimonial desde el enfoque patrimonial en sí mismo, que es conservar, restaurar y/o mantener en buenas condiciones el bien mueble o inmueble cultural, y el efecto que este tiene respecto a su ubicación. Y es que, si bien, se encuentran en ciudades como Lima o Quito, declaradas como patrimonio histórico cultural, no se debe dejar de lado el contexto histórico y el rol que cumplieron en la historia.

En México, el Instituto Nacional de Bellas Artes, maneja un control del acervo e información del patrimonio nacional, así como el Fondo Nacional para la Cultura y las Artes, que por gestión ha logrado que el empresariado aporte en la conservación del patrimonio a través de deducciones de impuestos, haciendo una responsabilidad compartida e incluyente en este aspecto.

CARITAS (s.f.), organismo de la Iglesia del Perú promueve programas de voluntariado turístico en distintas regiones del país, como el que funciona en Ayacucho -ciudad de corte colonial- también llamado turismo solidario, 
donde impulsan actividades económicas a través de la actividad turística, favoreciendo a las comunidades e insertándolas en el desarrollo turístico de la región. Programa de nació al percibir que los pobladores solo eran espectadores y no participaban por no estar capacitados para ofrecer los servicios turísticos. Es así, que se implementan microempresas y talleres productivos artesanales rescatando las potencialidades y aptitudes de los habitantes de la comunidad, los cuales, son incluidos en la cadena productiva, propiciando un desarrollo turístico sostenido.

\section{Gestión del turismo cultural}

Salgueiro (2001) propone una definición del proceso de gestión asumiéndola como un conjunto de actividades que conducen al logro de objetivos y metas planificados con anterioridad.

Por otra parte, turismo es concebido como un hecho humano eminentemente social, multidisciplinario y multisectorial, por consiguiente cambiante, que debe adecuarse a las circunstancias y avances de un mundo cada vez más globalizado. De hecho, hay mucho que aportar aún, por lo que es importante contar con modelos donde patrimonio e identidad se constituyan en elementos sustanciales que permitan la valoración del Conjunto Monumental de Santo Domingo mediante un plan de marketing.

Turismo y cultura son un binomio de términos que relacionan directamente el patrimonio cultural con el medio ambiente, social urbano y la motivación del visitante; cuyo desplazamiento se origina por el interés de explorar una ciudad con valores históricos, religiosos, arquitectónicos, artísticos, etc. Al respecto, la Organización Mundial de Turismo - OMT (2016) define al turismo cultural como: «Los movimientos de personas para satisfacer la necesidad humana de diversidad orientadas a elevar el nivel cultural del individuo, facilitando nuevos conocimientos, experiencias y encuentros».

Es así que el posicionamiento de un producto o servicio consiste en resaltar sus características a través de una comercialización adecuada, basados en criterios de competencia y respetando las reglas de la sociedad. 
La gestión favorecería la difusión y promoción del valor innegable de Santo Domingo y sus aportes en el campo histórico, religioso, arquitectónico y artístico, resaltando la importancia que tiene para la historia e identidad de los peruanos.

Los monasterios integrados en circuitos turísticos de Lima Colonial, ofrecen un tour descriptivo de los claustros e iglesias. En el caso de Santo Domingo, es posible ofrecer programas y actividades de orden religioso y cultural, además de los servicios religiosos propios. En consecuencia, el Conjunto Monumental de Santo Domingo cuenta con elementos tangibles e intangibles y otros complementarios en el Centro Histórico que hacen del producto a mostrar una oferta autosuficiente, con la posibilidad de ser elegido y fidelizar turistas potenciales.

\section{Patrimonio e identidad}

Se puede afirmar que patrimonio e identidad actúan juntos para consolidar y sustentar las bases de la nacionalidad peruana sobre un territorio de pertenencia, con historia, pasado, presente y futuro; que se une a los bienes materiales e inmateriales; a lo espiritual y también sentimientos. Con idiosincrasia, usos y costumbres resultantes de un sincretismo entre lo religioso y cultural, que tomó su tiempo y dio por resultados una fusión.

Al patrimonio corresponden bienes (tangibles e intangibles) del pasado, heredados de nuestros antepasados con una fuerte carga emotiva por lo que representan y que es valorado por la generación actual en el mismo lugar de arraigo. Este patrimonio nos permite demostrar una identidad con conocimiento y ser partícipes actuales de la historia. Alguna vez seremos parte de ese pasado al que hacemos referencia hoy.

La responsabilidad de la conservación del patrimonio corresponde a la comunidad. Una de las razones más antiguas para conservar los bienes culturales de la ciudad de Lima, es sin duda el aspecto religioso que a través de un patrimonio unido a la fe, sentimiento y tradición, da paso a la creación de una devoción con identidad, de la cual somos responsables. 
El patrimonio histórico de Lima, en particular, es una parte importante de la memoria de la nación y su conservación permite evidenciar la fisonomía de la ciudad como ciudad histórica monumental. Lima, incluso, fue fundada sobre el mismo territorio perteneciente al Cacicasgo de Taulichusco.

Existen en esta ciudad restos arqueológicos que son parte de este patrimonio. La legislación vigente en el país prevé su conservación, sin embargo, parte del problema es la alteración, demolición u ocupación con otros fines, donde piezas históricas terminan en manos de coleccionistas y fuera del país.

En lo que respecta a la identidad nacional, quien fuera Presidente de la Academia Nacional de Historia, José Agustín de la Puente Candamo, (como se citó en Guerra-Martiniere, Olguín-Callo, \& Gutiérrez-Muñoz, 2002) enaltece a Santo Toribio de Mogrovejo y lo reconoce como uno de los grandes forjadores de la nacionalidad por ser, precisamente, el gran educador del hombre de la sociedad peruana.

Por su parte, desde una visión antropológica Matos-Mar (1984) analiza los grandes cambios y reacciones de las masas populares frente a un Estado impositivo y de economía en crisis. Además, indica la necesidad de integrar, a través del diálogo, a las grandes mayorías con las instituciones que gobiernan, logrando concebir una sola nación. De lo contrario, señala, prevalecerá el caos, que a futuro, solo ahondará los problemas que nos aquejan como sociedad y por ende no ayudará a formar una identidad que solidifique un solo sentimiento como peruanos.

Si partimos del reconocimiento de una diversidad de los componentes de una nación, aceptando sus diferencias con sentido de equidad y pertenencia hacia el país, con una misma condición de ciudadanos, debemos reconocer y asimilar la heterogeneidad como una característica propia de nuestra sociedad, ayudándonos a identificarnos por el valor e importancia de haber nacido y coexistido en este país.

Para Giddens (2000), el término etnia, está referido a lo físico, rasgos distintivos de origen biológico, genético y aspectos culturales. Aduce que 
se gestó así una oposición entre lo serrano y costeño; indio y criollo; rural y urbano, que a pesar de los líderes independentistas y la naciente república, no se pudo superar las diferencias e ir hacia una unidad como nación peruana emergente. Queda esa ausencia de nación de identidad, sucede aún, sin poder encontrar un balance entre lo que es la herencia andina y colonial.

Mientras que el Estado peruano reconoce y protege su diversidad étnica y cultural constitucionalmente, al ser un país multiétnico. Asimismo, organismos internacionales reconocen la diversidad cultural y etnolingüística del Perú, cuya variación está en permanente cambio a lo largo de la historia peruana. Motivo por el cual Inca Garcilaso de la Vega se debatió entre estos pensamientos. Se preguntó quién era él, a pesar de aceptar el mestizaje y de tener un alto concepto del peruano y de su historia.

Desde la perspectiva psicológica Salgado (1999) aborda la identidad desde las áreas cognitiva, afectiva, social, etc. Según su estudio un porcentaje mayoritario cree que la identidad está en plena construcción y que en la actualidad existe una crisis de identidad nacional por el hecho de tener muchas identidades nacionales. A su vez, plantea que compartimos un mismo pasado, presente y futuro, pero no igualitario; que existen intereses generales, particulares, y otros muy particulares, producto de la corrupción y crisis de valores. Sostiene además, que socialmente el peruano sabe manifestar abiertamente lo que piensa, creencias y aspiraciones personales; defiende sus derechos pero se manifiestan con pasividad; son conformistas y consideran como válido cualquier método para lograr el éxito.

Por otro lado, el problema en la formación de la identidad nacional tiene causas de orden socioeconómico, cultural, educativo e ideológico. Y que se generaría un cambio si se reducen las tasas de analfabetismo y se mejora la calidad en la educación. Cabe mencionar que el núcleo familiar dentro de una formación religiosa constituye una base para la formación de una persona con principios y valores, capaz de tener una vida de sólida formación moral.

Las difíciles circunstancias de grandes sectores y las diferencias sociales y económicas, paralelo al proceso de regionalización y descentralización (no siempre bien entendida) hacen que haya una reacción de la población en general, que contribuye a los sucesivos problemas de orden coyuntural, 
donde la mayoría de ciudadanos no percibe soluciones por la falta de equidad y distribución de los bienes nacionales.

Finalmente, según Hernández (2000), la incorporación del Perú al mundo occidental se produjo en tres dimensiones: social, cultural y étnico. Conociendo las diferentes características de nuestras tradiciones, surge la incertidumbre por saber qué condiciones nos hacen capaces de tener una historia en común y a la vez aceptar los cambios que nos trae el futuro.

A todo esto, agregar el proceso de globalización que impone reglas debido a las economías y juego de mercado por oferta y demanda, acentuando las diferencias y desbalances entre países y regiones con mayores y/o menores posibilidades de desarrollo.

\section{Obra evangelizadora de los dominicos}

Los dominicos enseñaron el evangelio desde su llegada así como participaron en la instrucción educativa, llegando a fundar importantes colegios y centros superiores de estudios dentro de los principios de la religión católica. La influencia de la misión apostólica de los dominicos ha sido continua en la vida de los peruanos. Destacaron ilustres religiosos, no solo de la Orden de Predicadores, también franciscanos, agustinos y jesuitas, quienes trataron humanamente a los indígenas que fueron maltratados por las autoridades de la colonia quienes los explotaban. Son testimonio de ello los santos peruanos que contribuyeron dedicando sus vidas a menguar los sufrimientos con actos de bondad, justicia, paz y amor por el prójimo.

Los misioneros bautizaron y procedieron a la catequización enseñando a los indígenas el castellano para celebrar los misterios de la fe. Los elementos empleados en la evangelización fueron: (a) las Doctrinas referidas a los contenidos de la fe cristiana; (b) la Encomienda, costumbre de origen feudal, a través de la cual los encomenderos imponían a los naturales un conjunto de obligaciones con la condición de sostenerlos en lo económico y educarlos cristianamente. El encomendero era abusivo, en muchos casos se apropió de los bienes de los indígenas. Los dominicos cumplieron el rol de reclamar y denunciar estos abusos ante las Cortes de España, destacando el célebre Fray Bartolomé de las Casas y Fray Tomás de San Martín; y (c) las Reducciones, 
que obligaba a los nativos a vivir en poblados cerca de los españoles y así concentrarlos para facilitar el cobro de tributos (Málaga-Medina, 1969). En las reducciones existía una adecuada organización religiosa, social y política, es allí donde los misioneros realizaban la tarea de evangelizar. Apoyados por traductores, inicialmente, las realizaban durante unas horas los domingos y las grandes festividades, acción a la que nunca renunciaron porque la consideraron su misión esencial. Esta metodología suponía que el misionero no debía acompañar al militar conquistador, ni vivir con el explotador encomendero, tampoco mezclarse con los traficantes de esclavos o herir con su voz, tal como como lo hacían los capataces y autoridades.

A tal punto llevaron a cabo su defensa y protección, que algunos fueron asesinados por negarse a abandonar su labor o ayudar a los oprimidos a rebelarse huyendo del trato inhumano que recibían de encomenderos y autoridades. Por ello, consideraron necesario hablar lenguas oriundas de cada lugar, con el fin de tener mejor comunicación y así predicar en el idioma de los nativos. Como prueba testimonial de ello, se pueden encontrar actas de Capítulos Provinciales de la Orden, elaboradas con gramática y vocabulario en lenguas originarias. Así tenemos a Domingo de Santo Tomás, autor de la primera gramática en lengua quechua; también a Santo Domingo de Santa María, Benito Hernández, Domingo de Vico y otros más. Precisamente, en los trabajos científicos de José Alvarez, Pío Aza y Ricardo Alvarez Lobo se puede apreciar esta labor filológica. En la actualidad, los misioneros dominicos continúan con este compromiso, concretizado en acciones de protección y defensa de los más necesitados en América Latina y el Caribe (Torres, 2013).

\section{Conjunto Monumental de Santo Domingo y la gestión turística de Lima}

La orden dominica posee un patrimonio e identidad histórica, religiosa, arquitectónica y artística que es digno de ser admirado y atendido por el mundo turístico. Para ello, es necesario tener un plan de gestión que promueva la responsabilidad por el cuidado y preservación, cuya dirección administrativa de la gestión turística se encuentre a cargo de los miembros de la orden dominica, apoyados por las autoridades de la ciudad y con la 
participación de sus ciudadanos; siendo esta gestión inclusiva con los sectores más necesitados previamente capacitados.

El patrimonio cultural por definición es todo producto de la creatividad humana que nace de las necesidades del hombre, quien obtiene un provecho del recurso de su medio natural, en el cual vive, con el fin de mejorar sus condiciones de vida y perpetuarlas a través de generaciones venideras.

El turismo asociado al patrimonio histórico es una combinación de motivación recreativa con conocimiento y verificación de saberes culturales; regresar al pasado visitando en el presente, recorriendo lugares y recordando los hechos más significativos de su historia. Así, tenemos al fundador del primer hospital, ubicado en Santa Ana, don Jerónimo de Loayza y la creación de la primera universidad en América, por Fray Tomás de San Martín, la Universidad Nacional Mayor de San Marcos, que tomó el nombre de un apóstol y que funcionó sus primeros años en el propio convento de Santo Domingo.

El patrimonio religioso presenta evidencia de la importancia de la Orden desde el Virreinato. La organización de la Iglesia Católica del Perú, por el dominico Santo Toribio de Mogrovejo; los santos nacidos en el Perú como Santa Rosa de Lima, San Martín de Porres.

En cuanto al patrimonio arquitectónico y artístico tenemos las estructuras virreinales, principalmente las del siglo XVII. Sobresalen por sus obras en esta época alarifes y maestros de obra, entre ellos, Fray Diego Maroto y Manuel de Escobar, quienes hicieron aportes en estilos arquitectónicos, cambiando del gótico isabelino a la arquitectura barroca metropolitana.

Brillaron en las artes, principalmente en teatro, intelectuales de colegios y universidades influenciados por autores y escritores europeos. El público que asistía veía reflejada su propia realidad social. Se presentaban en ambientes palaciegos distinguidos y otros populares como los corrales de comedias al aire libre. Peralta y Barnuevo era un polifacético creador de personajes y canciones. El teatro religioso, por su parte, elegía temas bíblicos y autos de fe, como la obra de teatro religioso indígena de Usca Paucar. 
La visita al Conjunto Monumental de Santo Domingo comprende el recorrido por el interior del convento, en el cual destaca el salón de portería, el primer claustro, la escalera principal, la biblioteca, la sala capitular, la cripta principal, el segundo claustro, la capilla de San Martín de Porres, el antiguo claustro de enfermería y la capilla de Santa Rosa de Lima. Prosiguiendo el recorrido se pasa a la sacristía, el templo, el coro, la cúpula y se termina con la subida a la torre. Todos los ambientes ostentan estilos artísticos donde se destaca la arquitectura y decoración de la época virreinal. Entre sus paredes, esculturas, pinturas y reliquias guarda su propia historia y evidencia de la vida espiritual durante más de cuatrocientos cincuenta años.

\section{Método}

El tipo de investigación es aplicada, transversal, no experimental. No se manipula ninguna de las variables y se observa el fenómeno tal cual.

Las variables son:

Independiente $(X)$ = Patrimonio e identidad

Dependiente $(\mathrm{Y})=$ Gestión del producto

La variable independiente es el Patrimonio e identidad histórica, religiosa, arquitectónica y artística del Conjunto Monumental de Santo Domingo.

La variable dependiente es Gestión del producto turístico cultural de la ciudad de Lima, como se puede apreciar en la Tabla 1, tanto la variable independiente como la variable dependiente tienen dimensiones e indicadores.

\section{Participantes}

Se observó la fluctuación de los visitantes nacionales y extranjeros, de lunes a domingo durante el mes de agosto de 2016, en horario para visitas al Conjunto Monumental de Santo Domingo.

De acuerdo a lo registrado el promedio ponderado para la población fue de 246 personas, de lo cual se estableció, por medio del programa On 
Tabla 1

Matriz de operacionalización de las variables

\begin{tabular}{|c|c|c|}
\hline VARIABLE & DIMENSIONES & INDICADORES \\
\hline $\begin{array}{l}\text { Independiente } \\
(X)=\text { Patrimonio e Identidad }\end{array}$ & $\begin{array}{l}\text { X1 = Histórico, Religioso } \\
\text { Trascendencia de hechos marcan la } \\
\text { vida de un país, región o institución con } \\
\text { marcadas características como para ser } \\
\text { reconocidas en el tiempo, en el ámbito } \\
\text { cultural y religioso, en el caso de la } \\
\text { presente investigación. }\end{array}$ & $\begin{array}{l}\text { X1.1 = Nivel de Calidad de la labor } \\
\text { evangelizadora de los dominicos } \\
\text { X1.2= Nivel en que es reconocida } \\
\text { en la historia el aporte de los } \\
\text { dominicos a la identidad peruana. }\end{array}$ \\
\hline $\begin{array}{l}\text { Abarca el legado que se hereda de } \\
\text { una cultura que fija su residencia en } \\
\text { un ámbito geográfico en el medio el } \\
\text { cual se adapta y crea sus propias } \\
\text { costumbres y convicciones, } \\
\text { formando una sociedad cultural con } \\
\text { el cual se distinguen los pobladores } \\
\text { y se sienten parte de ella, creando } \\
\text { un sentimiento de arraigo hacia sus } \\
\text { raíces y sus ancestros, tanto en } \\
\text { forma material como espiritual }\end{array}$ & $\begin{array}{l}\text { X2 = Arquitectónico, Artístico. } \\
\text { Manifestaciones de la creatividad } \\
\text { humana para expresar estilos } \\
\text { temporales en artes plásticas en } \\
\text { construcciones y decoraciones } \\
\text { aplicando técnicas que crean ilusión } \\
\text { y perspectivas realizadas por un } \\
\text { artista determinando tendencias y } \\
\text { épocas. } \\
\text { X3 = Identidad sociocultural }\end{array}$ & $\begin{array}{l}\text { X2.1= Nivel de importancia } \\
\text { arquitectónica de Santo Domingo } \\
\text { X2.2= Nivel de importancia artística de } \\
\text { la Iglesia y Convento de Santo } \\
\text { Domingo } \\
\text { X3 = valoración y sentimiento común } \\
\text { de pertenencia hacia los bienes } \\
\text { materiales patrimoniales. }\end{array}$ \\
\hline
\end{tabular}

\begin{abstract}
Dependiente $(Y)$
Gestión del producto

La gestión del producto comprende la sistematización de la oferta principal y secundaria del producto que juntos constituyen la razón de ser de la revaloración del conjunto religioso de Santo Domingo a fin de cumplir con los objetivos del trabajo de investigación.
\end{abstract}

Y1 = Nivel de Aceptación en la Gestión del Producto de la Iglesia y Convento de Sto. Domingo.

Y2 = Valoración del Patrimonio Arquitectónico y Artístico en la Gestión del Producto Turístico.

Y3 = Gestión Cultural del Producto Turístico
Y1.1 = Proceso administrativo Consensuar los elementos

Conformantes: planificación, organización, dirección y control de una gestión que beneficie a Sto. Domingo a través del turismo.

Y1.2 = Plan de marketing Determinar acciones que permitan cumplir los objetivos propuestos innovando un producto original cultural,religioso y turístico de Sto. Domingo.

Y1.3 = Reconocer el nivel de importancia y valoración del conjunto de Santo Domingo en la gestión y aporte cultural a la actividad turística del C.H.L.

Nota: Elaboración propia. 
Line NetQuest, la muestra de 150 participantes: 50\% mujeres y 50\% varones. En cuanto a la edad 33.33\% estuvieron entre 34 y 41 años; 32.67\% entre 26 y 33 años; $19.33 \%$ entre 18 y 25 y 14.67\% de 42 años o más. En cuanto a la nacionalidad $54.67 \%$ fueron visitantes extranjeros, mientras que $45.33 \%$ visitantes nacionales.

\section{Instrumentos}

- Cuestionario a visitantes de Santo Domingo. Contiene 17 ítems, cada uno de ellos con alternativas de respuestas cerradas evaluando aspectos característicos de los visitantes, como la nacionalidad, sexo, edad, temporadas, motivos de visita, ocupación, tiempo promedio de visita, conocimiento e importancia de la visita, entre otros ítems. Además, se realizaron entrevistas a dos religiosos dominicos y un laico comprometido y se elaboró un análisis FODA.

\section{Resultados}

A través del análisis de los datos recogidos se determina que sí influye la variable independiente $(X)$ Patrimonio e identidad sobre la variable independiente (Y) Gestión del producto turístico cultural de Lima (Tabla 2).

Tabla 2

Prueba de hipótesis Chi cuadrado (hipótesis general)

\begin{tabular}{lllc}
\hline \multicolumn{4}{c}{ Pruebas de chi-cuadrado } \\
\hline & Valor & $d f \quad \begin{array}{c}\text { Significación } \\
\text { asintótica } \\
\text { (bilateral) }\end{array}$ \\
\hline Chi-cuadrado de Pearson & $283.689^{*}$ & 210 & .001 \\
Razón de verosimilitud & 217.088 & 210 & .354 \\
Asociación lineal por lineal & 20.661 & 1 & .000 \\
Número de casos válidos & 150 & & \\
\hline
\end{tabular}

Nota: Elaboración propia.

* 258 casillas $(100 \%)$ han esperado un recuento menor que 5. El recuento mínimo esperado es .04. 
Tabla 3

Prueba de hipótesis Chi cuadrado (hipótesis específica 1)

\begin{tabular}{lllc}
\hline \multicolumn{3}{c}{ Pruebas de chi-cuadrado } \\
\hline & Valor & $d f$ & $\begin{array}{c}\text { Significación } \\
\text { asintótica } \\
\text { (bilateral) }\end{array}$ \\
\hline Chi-cuadrado de Pearson & $77.237^{*}$ & 65 & .142 \\
Razón de verosimilitud & 75.754 & 65 & .170 \\
Asociación lineal por lineal & 4.383 & 1 & .036 \\
Número de casos válidos & 150 & & \\
\hline
\end{tabular}

Nota: Elaboración propia.

* 80 casillas $(95.2 \%)$ han esperado un recuento menor que 5. El recuento mínimo esperado es .04.

\section{Tabla 4}

Prueba de hipótesis Chi cuadrado (hipótesis específica 2)

\begin{tabular}{lllc}
\hline \multicolumn{4}{c}{ Pruebas de chi-cuadrado } \\
\hline & Valor & $d f$ & $\begin{array}{c}\text { Significación } \\
\text { asintótica } \\
\text { (bilateral) }\end{array}$ \\
\hline Chi-cuadrado de Pearson & $102.876^{*}$ & 25 & .000 \\
Razón de verosimilitud & 74.775 & 25 & .000 \\
Asociación lineal por lineal & 33.941 & 1 & .000 \\
Número de casos válidos & 150 & & \\
\hline
\end{tabular}

Nota: Elaboración propia.

* 27 casillas $(75 \%)$ han esperado un recuento menor que 5 . El recuento mínimo esperado es .20 .

En cuanto a patrimonio e identidad histórico y religioso de Santo Domingo se establece que sí influye sobre la gestión del producto turístico cultural de Lima (Tabla 3).

En cuanto a patrimonio e identidad arquitectónico y artístico de Santo Domingo se establece que sí influye sobre la gestión del producto turístico cultural de Lima (Tabla 4). 


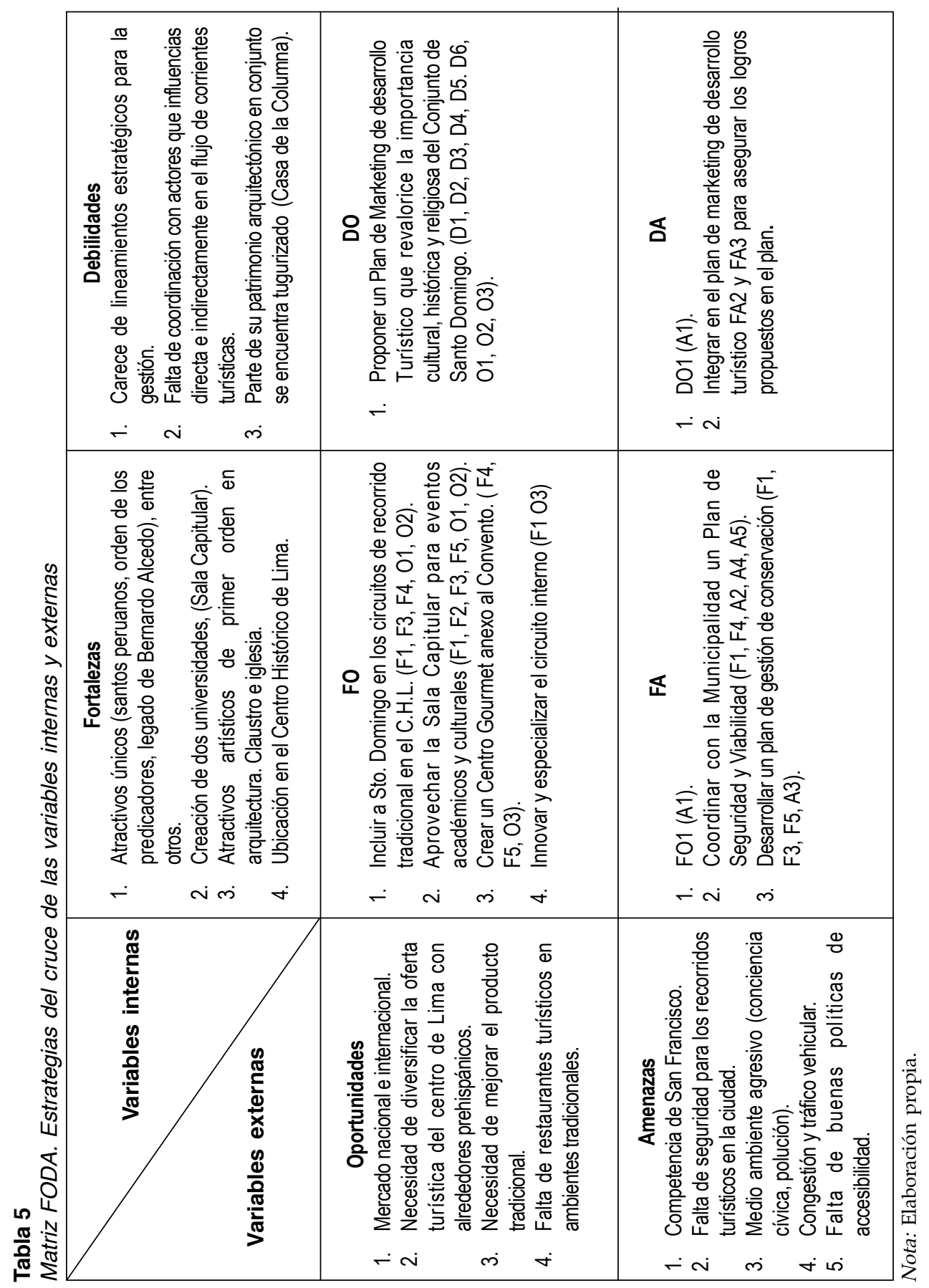


La aplicación de las entrevistas realizadas a expertos se analizó a través de la metodología de la triangulación. Consensuando las tres opiniones de los expertos se determina la necesidad de salvaguardar y valorar aún más el patrimonio. Asimismo, los expertos coinciden en señalar que la Orden debe sensibilizar y concientizar al público a través de un programa que incluya y que forme en compromiso y responsabilidad respecto de sus patrimonios. Para lograrlo, concluyen en que se debe crear un modelo de gestión.

Finalmente, por medio del FODA se establecieron las fortalezas, debilidades, oportunidades y amenazas (Tabla 5).

\section{Conclusiones}

- El patrimonio e identidad de Santo Domingo sí influyen en la gestión del producto turístico religioso cultural de Lima, porque el patrimonio tangible e intangible; histórico religioso, arquitectónico y artístico que posee este conjunto monumental reflejan la imagen de una época colonial en su estructura física, que se distingue dentro del centro histórico de Lima, declarado Patrimonio Cultural de la Humanidad. Igualmente por la labor evangelizadora y educativa en el propio idioma de los nativos, los dominicos han contribuido a la formación de la identidad peruana, sabiendo enseñar y fusionar conocimientos de una nueva cultura en un proceso de transculturización, ganándose la confianza y afecto, hechos determinantes para influir en la creación y gestión de un producto turístico religioso cultural de calidad.

- La gestión del producto turístico es factible de mejorar y lograr un posicionamiento expectante en el contexto de turismo religioso cultural de Lima colonial, dada sus ventajas competitivas. Ya que la orden dominica posee un patrimonio histórico, religioso, arquitectónico y artístico que es digno de ser admirado y atendido por el mundo. Por ello, es pertinente tener un plan de gestión que promueva la responsabilidad por el cuidado y preservación.

- Patrimonio e identidad actúan juntos para consolidar y sustentar las bases de la nacionalidad peruana sobre un territorio de pertenencia, con historia, pasado, presente y futuro; se une a los bienes materiales e 
inmateriales, a lo espiritual y también a los sentimientos. Con idiosincrasia, usos y costumbres resultantes de un sincretismo entre lo religioso y cultural, que tomó su tiempo y dio por resultado una fusión.

- No es fácil gestionar el turismo e integrarlo a una estructura urbana que no ha sido preparada porque sus habitantes no saben apreciar, cuidar y conservar «lo suyo». La gestión del producto turístico cultural en la ciudad de Lima debe optimizarse con el fin de tener un producto turístico sostenible y consolidado. Debemos tener en cuenta que no basta con la descripción de los numerosos elementos patrimoniales, dado que turismo es una actividad multisectorial con compromiso y también una herramienta de desarrollo para valorar el patrimonio.

- Los resultados del presente trabajo determinan que sí influye la variable independiente Patrimonio e identidad sobre la variable dependiente Gestión del producto turístico cultural de Lima. Lo mismo ocurre con respecto al patrimonio e identidad histórico, religioso, arquitectónico y artístico de Santo Domingo, estableciendo que sí influye sobre la gestión del producto turístico cultural de Lima.

- Las entrevistas realizadas a expertos en el tema confirman la necesidad de salvaguardar y valorar el patrimonio. Se concluye, finalmente, que la gestión del producto turístico es factible de mejorar y lograr un posicionamiento expectante en el contexto, dada las ventajas competitivas del Conjunto Monumental de Santo Domingo.

\section{Recomendaciones}

- Reformular el producto religioso cultural actual que ofrece, aplicando el plan de marketing, producto del aporte de la presente investigación. La finalidad es posicionar a Santo Domingo y distinguirlo con una oferta histórica, religiosa, arquitectónica y artística, muy difícil de igualar.

- Tramitar las coordinaciones necesarias con las autoridades de las dos universidades vinculadas con la historia de los dominicos en el Perú, especialmente con las escuelas de turismo para incentivar la ejecución de investigaciones y especialización cuyo fin sea valorar a Santo Domingo. 
- Impulsar un centro de documentación de coparticipación y cooperación mutua entre las dos instituciones académicas vinculadas, desde su creación, a la orden dominica. Motivados por el incalculable material documentario existente de la participación de los dominicos en la formación de la identidad peruana. Facultades de turismo, sociología, antropología, psicología y muchas otras, podrían tener campos de investigación.

- Promover, en los dominicos, la toma de acciones que conlleven mayor difusión y facilidades para el conocimiento y visita a los ambientes y capillas destinadas al culto de San Martín de Porres, Santa Rosa de Lima y San Juan Masías, representantes ilustres de los dominicos y santos peruanos. El producto turístico debe resaltar el valor histórico, religioso, arquitectónico y artístico del Conjunto Monumental de Santo Domingo, teniendo como misión el interés y satisfacción de sus visitantes; y como visión, lograr un turismo cultural sostenible convirtiéndose en un modelo de gestión de turismo.

- Los dominicos y su encomiable labor evangelizadora, desde tiempos de la conquista y que perdura aun en la actualidad, son quienes con la participación de los miembros de la comunidad y las autoridades pueden llevar adelante el plan de gestión propuesto; siendo esta participación inclusiva, favoreciendo a los sectores más necesitados.

- Desarrollar eventos académicos, empresariales, comerciales, artísticos, gastronómicos y folclóricos en las instalaciones como exposiciones, conciertos, obras teatrales, ceremonias, etc. La riqueza tangible e intangible del Conjunto Monumental de Santo Domingo destaca sobre las existentes en el centro histórico de Lima. Uso de las salas para el desarrollo de actividades académicas y de investigación como seminarios, congresos, por ejemplo, la hermosa Sala Capitular.

- Proponer programas turísticos religiosos que se desarrollen dentro del Conjunto Monumental y que también incluya otros atractivos de la periferia. 
- Implementación de un restaurante o un espacio para degustar potajes y dulces cuyo origen se remonte a etapas de la historia. Así como la venta de artículos y recuerdos de la visita, personalizados o que se distingan de los ofrecidos alrededor.

- Se debe mejorar la seguridad y el orden en el Centro Histórico, así como las facilidades para el estacionamiento vehicular de los visitantes.

\section{Referencias}

CARITAS. (s.f.). Turismo solidario. Recuperado de http://www.turismosolidario@caritas.org.pe

Guerra-Martiniere, G., Olguín-Callo, O., \& Gutiérrez-Muñoz, C. (Eds.). (2002). Sobre el Perú. Homenaje a José Agustín de la Puente Candamo. Lima: Fondo editorial PUC.

Giddens, A. (2000). Modernidad e identidad del yo: el yo y la sociedad en la época contemporánea. Barcelona: Península.

Hernández, M. (2000). ¿Es otro el rostro del Perú? Identidad, diversidad y cambio. Lima: Agencia.

Leuridan, J. (2014). La Familia, la escuela y los líderes de la sociedad. Cultura, 28, 11-89. Recuperado de http:/l www.revistacultura.com.pe/revistas/RCU_28_1_la-familia-la-escuela-y-los-lideres-de-la-sociedad-Johan-LeuridanHuys.pdf

Málaga-Medina, A. (1969). Las Reducciones en el Perú. Kollasuyo. Recuperado de http://www.iheal.univ-paris3.fr/ sites/www.heal.univ-paris3.fr/files/las\%20reducciones\%20en\%20el\%20Peru\%20Malaga.pdf

Matos-Mar, J. (1984). Desborde popular y crisis del Estado. El nuevo rostro del Perú en la década de 1980. Lima: IEP - Instituto de Estudios Peruanos.

Organización Mundial del Turismo - OMT. (2016). Definiciones. Recuperado de www2.unwto.org/content/definicion

Salgado, C. (1999). ¿Quiénes somos los peruanos? Una perspectiva psicológica de la Identidad Nacional. Lima, Perú: Universidad de San Martín de Porres.

Salgueiro, A. (2001). Indicadores de gestión y cuadro de mando. Madrid: Díaz de Santos.

Torres, S. Op. (2013). Misioneros dominicos. Boletín Informativo, 199, 1-56. Recuperado de https//issuu.com/ boletinmisionerosdominicos/docs/199-2013

United Nations Educational Scientific and Cultural Organization - UNESCO. (1997). Nuestra diversidad creativa (Informe de la Comisión Mundial de Cultura y Desarrollo). Madrid: Santa María Ediciones. Recuperado de http:/l unesdoc.unesco.org/images/0010/001036/103628s.pdf

El presente artículo tiene de base la investigación realizada en "El patrimonio e identidad de Santo Domingo y la gestión del producto turístico cultural de Lima" sustentada en la Universidad de San Martín de Porres por la autora. 